\title{
A review of composite leaf springs for automotive vehicles
}

\author{
Brighton Manaba ${ }^{1 *}$, and Vuyo T Hashe ${ }^{1}$ \\ ${ }^{1}$ University of Johannesburg, Doornfontein, South Africa
}

\begin{abstract}
In the quest to conserve natural resources and economic energy. Weight reduction has been the focus of auto-manufactures and the aerospace industry in the present day. Weight reduction can be archived primarily by introducing better design optimization, better material, and improved manufacturing processes. This approach by introducing composite materials into automobile industries, which has high strength to weight ratio and excellent corrosive resistance, can fulfil the requirement. This review paper investigates the use of composite materials in the design of leaf springs for automotive vehicles. The paper underscores the suitability of composite materials for leaf spring in automobiles and develops a new leaf spring design that optimizes weight reduction and strength. The review provides details regarding previous efforts conducted on the design of leaf springs while outlining the knowledge gap areas. This review commences with an introduction to leaf springs and a brief history of their development. Followed by the properties that make an excellent leaf spring, this helps narrow down the information required for further developments providing avenues for possible future research.
\end{abstract}

\section{Introduction}

Leaf springs are essential elements in the suspension systems of vehicles including sport utility vehicles, trucks, SUVs, and railway carriages. The purpose of leaf springs is to separate and protect the vehicle chassis from vibrations that it experiences as it travels over rough and bumpy terrain [1]. Additionally, they aid in giving control to the wheels during braking acceleration and general vehicle manoeuvres experienced during road undulations [2]. Present-day, the automobile and aerospace industry face rapidly growing competition to improve existing products [3]. Their quest aims at conserving natural resources and economizing energy through weight reduction. Weight reduction can be achieved primarily by the introduction of improved designs that save on material use, better manufacturing processes and better materials. Driven by the goal to reduce vehicle weight, interest has been drawn into the development of composite leaf springs, which have a higher strength to weight ratio than the conventional materials on the market. This paper studies various composite materials and geometries to find the best material and geometry that performs better than any existing leaf springs.

1 Corresponding author: vthashe@uj.ac.za 


\section{Leaf Springs}

Leaf springs were originally coined laminated or carriage springs. They are one of the oldest spring designs to ever existed, dating back to the 17th century [4] The design of leaf springs is quite distinct in that it does not carry the typical helical/ coil shape but rather a thin rectangular cross-section that spans along an arch-shaped length, see figure 1 below.

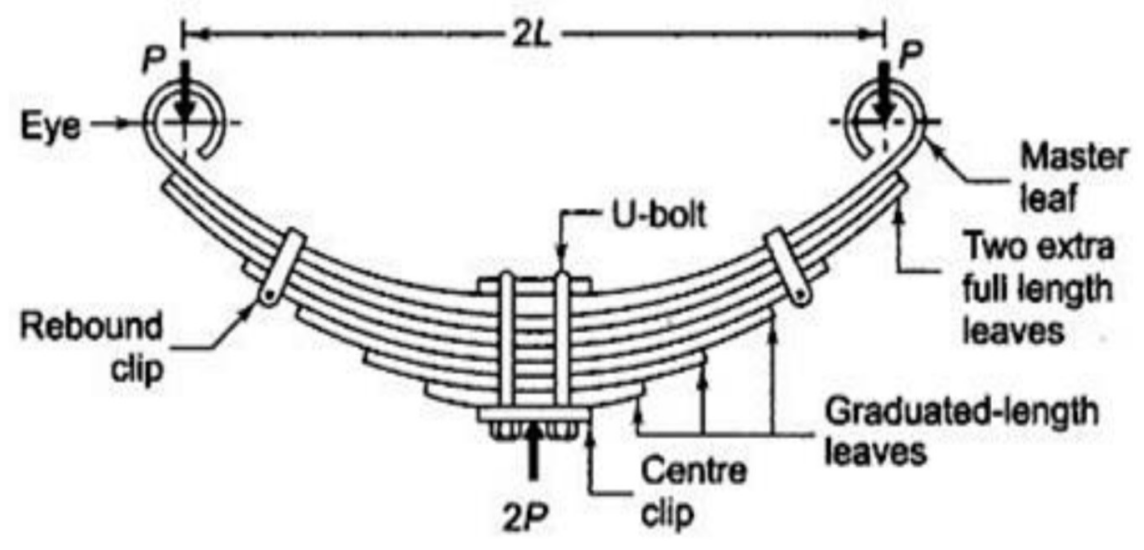

Fig. 1. Leaf springs [5].

To date, various designs of leaf springs have been developed, ranging from the elliptic design, three-quarter elliptic, quarter-elliptic and transverse, to the more modern designs, like the semi-elliptic, the parabolic leaf spring and finally the mono-leaf spring [6]. All these designs had their pros and cons; however, this section will only dissect the modern designs.

\subsection{Multi-leaf semi-elliptic}

This is the most common design in the history of leaf springs. It utilizes several layers of leaves stacked together, with the longest one on top and progressively shorter leaves following. The longest leaf spring is termed the master leaf, looped at both ends to allow for its attachment to the chassis [7]. The loops are known as the eye; following the master leaf, the second leaf is called the second master leaf. The rest of the other leaves are coined graduated leaves. The leaves are held together by what is not as U- clip; this allows for the distribution of stress among the leaves and prevents other leaves from buckling [8]. This design was advantageous in the sense that it also provided damping action for the vehicle. In addition, $t$ interleaf friction minimized the continued oscillation of the car [9]. However, this design had a drawback; the interleaf friction cannot be controlled and would at times result in unwanted stiction in the motion of the suspension. For this reason, a new design was implemented, the parabolic leaf spring.

\subsection{Parabolic leaf spring}

This design differs from the multi-leaf spring in that it has fewer leaves [10]. These leaves are also distinctively designed; they have a varying thickness along the parabolic length. This solves for stiction by preventing the leaves from touching except for the ends attached to the chassis and the centre attached to the axle [11]. In addition to the geometry, the design implements spacers that further help avoid any contact between the leaves. The characteristics of this design provided for the reduction in weight as compared to the older versions. It also offered suspension flexibility since interleaf friction is eliminated, translating to improved ride quality. However, this was not enough; further, development was made, which led to the mono-leaf spring design. 


\subsection{Mono leaf spring}

The first mono-leaf spring was design by Chevrolet, a British car manufacturing company [12]. The design was made specifically to solve the problem of weight and stiction caused by inter-leaf friction. To do away with inter-leaf friction, they proposed using only a single leaf instead of several leaves. The single leaf is made so that it can carry both static and dynamic loads without failure and having the capability to store enough shock energy. At the development of this design, a new material type was proposed- the composite material. The introduction of this material type revolutionized the design of leaf springs because it offers superior properties compared to the conventional steel used before. However, in as much as the mono-leaf spring design is ideal, it also provides new challenges; it does not offer the internal damping effects necessary to prevent continued oscillation of the vehicle. The problem, however, can be easily resolved by introducing power dampers.

\section{Materials}

Leaf spring's material considerations is one of the core areas of focus in this paper. The material used gives the spring its unique properties, which are required for its function. Such properties are maximum tensile strength and minimum modulus of elasticity. These properties provide, for higher specific strain energy (equation 1) one of the crucial properties for a leaf spring [13].

$$
S=1 / 2\left(\sigma^{2} / \rho E\right)
$$

This property means that the spring can store more strain energy and protect the chassis from undulations. The review will only focus on composite materials since the development is based on composite materials.

\subsection{Composite Materials}

Composites materials (composites) are formed by combining two or more materials to form one [14]. The combined materials do not react but instead, maintain a recognizable interface. The development of these materials is motivated by the fact that there is no available homogenous material with the desired characteristics for a given application [15]. For example, fibre materials are used in leaf springs because of the following properties: 1 High strength to weight ratio, 2 Lightweight, 3 Fire Resistance, 4 Chemical and weathering resistance, 5 Design Flexibility, and 6, Manufacturing Economy. Additionally, composite has superior fatigue properties [13], they are even used to repair metallic frames with fatigue damage [14]. In as much as composites are beneficial, they have limitations that include high raw material costs and usually high fabrication and assembly costs. However, the benefits that composites provide are far greater than their shortfalls.

\section{Review of past studies based on the analyses of different leaf spring designs}

In one of the recent studies made by Mahanthi and Murali [16], they made a comparative study between eight materials, four alloys and four composite materials to check which of the eight materials perform better when it comes to strength to weight ratio. Mahanthi and Murali used Computer Aided Three-Dimensional Interactive Application (CATDIA) to develop similar 3D models for each material and did the analyses using ANSYS's finite element analysis application. The study they made involved applying loads from $1000 \mathrm{~N}$ to $4000 \mathrm{~N}$. Each material was exposed to these four loads, and total deformation and equivalent stresses were noted. Based on the results of static analyses of both steel and composite leaf springs like EN47, KEVLAR, S-Glass Epoxy \& E-Glass Epoxy, the conclusion they 
drew was that Kevlar (composite material) performs best because it had the least weight and performed better in terms of strain energy, total deformation and equivalent stress.

In another study conducted by Prakash [17] in 2017, he limited his analysis to only two materials, steel $65 \mathrm{Si} 7$ representing the alloys and E-glass/Epoxy representing the composite materials. Prakash's design imperatives were stresses and deflections, again like Mahanthi and Murali. He did not build the designs but used CATIA (Computer Aided ThreeDimensional Interactive Application) to model designs and ANSYS finite element analysis to perform static analysis on the models. The investigation concluded that steel leaf springs are approximately $70 \%$ heavier than composite leaf springs and that they are they are muh more resilient to stressors than steel springs of the same design. Another significant outcome drawn from Prakash's investigation is that composite materials are 5 times more durable than conventional steel springs. In the paper "design and analysis of composite leaf springs" by Pinaknath [18], he investigates the effectiveness of composites leaf springs limiting his materials to only two, E glass /Epoxy (GFRP) for composites and $65 \mathrm{Si} 7$ steel for alloys just like Prakash [17]. He made the E-Glass/Epoxy design into a three-layered structure and perfomed both static and dynamic analyses on the models. He then compared his finding against the conventional leaf spring design. The results obtained concluded that composite materials are much stronger as they have less stress and deflections when exposed to loads, the material also possesses useful specific strain energy. Pinaknath also observes that composite materials are $67.88 \%$ lighter in weight than steel leaf springs and are an adequate replacement for both stiffness and stress.

Similar to the study carried by Pinaknath, Vivek Rai [19] in the paper he published on the development of composite leaf springs for lightweight commercial vehicles, in place of $65 \mathrm{Si} 7$ steel like Pinaknath he uses, EN47 steel. He also used different software to conduct his study, Pro-E wildfire 4.0 for 3D modelling and ANSYS for static analyses. Vivek's objective was to replace the multi-leaf steel spring with a mono composite leaf spring for the same loadcarrying capacity and stiffness. To do this, he compared EN 47 steel and composite materials (not specified). The finite element analysis results obtained are shown in Table 2 below.

Table 1. Finite element analysis results [19]

\begin{tabular}{|l|l|l|}
\hline Parameter & EN47 & Composite \\
\hline Load $(\mathrm{N})$ & 2446 & 2446 \\
\hline Max stress (MPa) & 738 & 570 \\
\hline Max Deformation (mm) & 25.4 & 24.6 \\
\hline FoS & 1.15 & 1.57 \\
\hline
\end{tabular}

From the results he obtained in table 2, Vivek concluded that transitioning from conventional steel springs to composite leaf springs was necessary. It is clear from the table that the yield stress and deformation of composite material have no significant difference from that of steel but, the use of composites contribute to a considerable reduction in vehicles weight; the benefits of the composite leaf springs outweigh its shortfalls.

Three years later, after Vivek's study, Sedlacek et al. [20] published a review on the design of composite leaf springs for railway vehicles; their focus was to design and optimize the railway leaf springs done first by numerical simulation then followed by an experimental test. The materials investigated were the glass fibre reinforcement with epoxy resin for composite materials. The material was modelled into the same shape and size as that of a conventional leaf spring. 


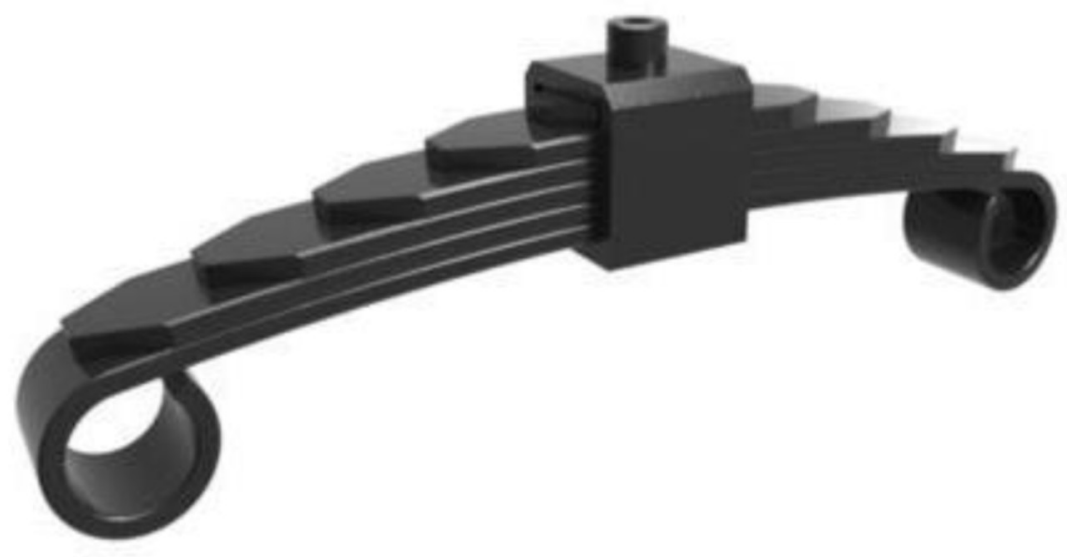

Fig. 2. Conventional Leaf Spring [20]

A maximum stress strength criterion and transverse shear interlaminar criterion were used to evaluate the failure index. From the investigation, the observations were assessed, and the comp

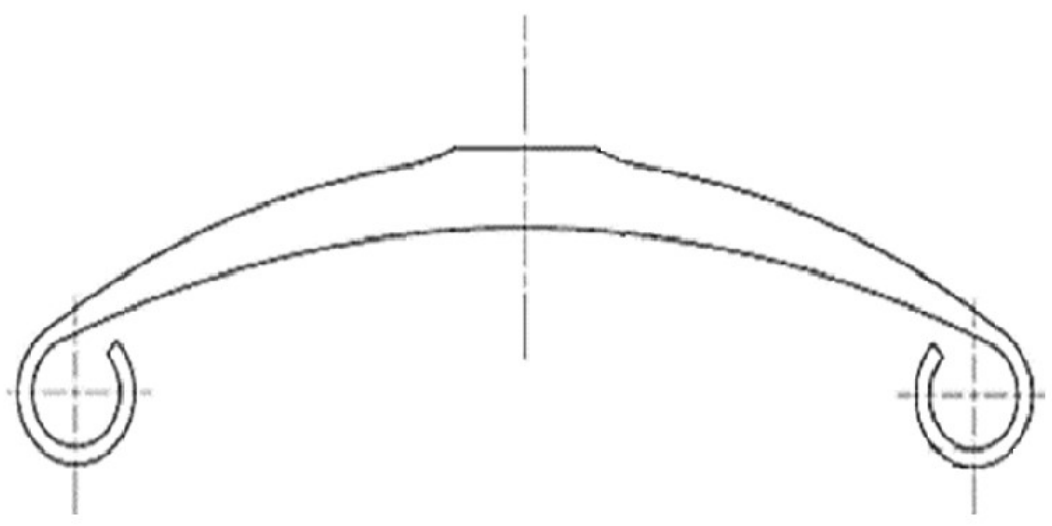

Fig. 3. The geometric parameters of the optimization of the leaf spring that was used [20].

Four years before the work published by Sedlacek et al., Venkatesan and Devaraj [21] conduct a similar study with more specified elements. The study focused on the materials in contrast to Sedlacek et al. study, which focused on geometry instead. The investigation of Venkatesan and Devaraj compared leaf springs made from steel with 0.9 to $1 \%$ carbon to those made from a composite material made from Glass/Epoxy reinforcements. Their study further investigated the effect of shape, using uniform cross-section leaf springs and those that are non-uniform (thicken as they approach the middle). The investigation was done using simulative software, 3D modeller for 3D drawing and ANSYS 10.0 for the finite element analyses.

Venkatesan and Devaraj drew two conclusions from their study; 1) the geometry of the leaf springs plays a significant role; it affects the performance of the leaf spring. Composite leaf springs with a thicker centre outperformed the ones with a uniform cross-section for strength. 2) From the comparative study they carried out between composite and steel leaf springs concerning weight and strength, it was observed that composite leaf springs are much lighter and have greater strength to weight ratio than steel leaf springs. Another similar study was carried out by Saini et al. [23] in 2013; their objective was to compare the stresses and weight- 
saving capabilities of three composite leaf springs made from different materials against steel made leaf springs. Saini et al. used Auto-CAD 2012 for 3D modelling, and the statistical analysis (stress and deformation) was done using ANSYS 9.0 software. The list of the materials and their performances are listed in the table below.

Table 2. Displacements and Von Misses stresses for the same loading conditions [23].

\begin{tabular}{|l|l|l|}
\hline Materials & Displacements $(\mathrm{mm})$ & Stress $(\mathrm{MPa})$ \\
\hline Steel & 10.16 & 453.92 \\
\hline Graphic epoxy & 15.75 & 653.68 \\
\hline Carbon epoxy & 16.21 & 300.3 \\
\hline E-glass epoxy & 15.89 & 163.22 \\
\hline
\end{tabular}

From the results obtained from their study, only graphite-epoxy has higher Von-Mises stresses than steel, meaning only graphite-epoxy can replace steel from the stress stiffness point of view. A comparative study was also made on the strength to weight ratio. The results they obtained are listed in the table below.

Table 3. \% saving of weight by using composites instead of steel [23].

\begin{tabular}{|l|l|l|}
\hline & Materials & $\%$ Weight saving \\
\hline 1 & Steel & - \\
\hline 2 & E-glass epoxy & 81.72 \\
\hline 3 & Carbon epoxy & 90.51 \\
\hline 4 & Graphite epoxy & 91.91 \\
\hline
\end{tabular}

Table 4 shows the percentage weight-saving measured against steel. Using either E-glass epoxy or Carbon epoxy of Graphite epoxy, there is $81.72,90.51,91.91$ cuts in weight, respectively. The conclusion drawn from their results was that composite materials perform better when weight reduction is considered than steel, with graphite-epoxy having the highest performance.

The above review covered the comparison of materials between composite materials and conventional steel materials extensively for leaf springs. The following reviews take a unique route. First, Papacz et al. [24] studied the ability of composite leaf springs to suppress vibrations. Amplitude and reactions of props were measured and recorded. Using these parameters, W. Papacz et al. [3] calculated the coefficients of vibration for composite leaf springs and steel leaf springs. From the analyses they made, they concluded that leaf springs made from composite materials have a more remarkable ability to suppress vibrations than steel springs. They also figured that composite materials are more comfortable to shape into any geometry and can be made into shapes with higher vibration suppression capabilities. Another unique approach was taken by Sam Varghese et al. They discussed the effects of shapes in the performance of leaf springs. They modelled two composite leaf springs made of glass fibre and with a polymer matrix, which was rectangular shaped (conventional); the 
other was trapezoidal. 3D models were drawn using solid works software, and the finite element one analysis was done using ANSYS 16.0. Table 5 shows the results of the investigation.

Table 4. [25]

\begin{tabular}{|l|l|c|}
\hline Cases & Deformation(m) & Equivalent Stress $(\mathrm{Pa})$ \\
\hline Conventional steel leaf spring & 0.0004301 & $1.6757 \times 10^{8}$ \\
\hline E-glass/Epoxy leaf spring & 0.0023004 & $1.3896 \times 10^{8}$ \\
\hline & 0.0013804 & $1.0391 \times 10^{8}$ \\
\hline
\end{tabular}

The conclusion drawn by Sam Varghese et al. was that composite materials reduce the weight by $85 \%$ if substituted for steel springs and that trapezoidal leaf springs are much superior to rectangular composite leaf springs.

\section{Conclusion}

A critical review of the development of composite leaf springs has been presented. The review ultimately concludes that composites are a suitable replacement for conventional steel. This is because of the unique properties that composites possess. The review has also shown ways to assess the performance of leaf springs both experimental and computational ones. The review, however, is subject to limitations in that, most of the work presented focused on computational analysis and less on experimental analysis. Goransson [26] argues that simulations do not precisely simulate real-life events as much as they are essential and accurate. Real-life experiments must be carried out to confirm the results obtained by the simulation. However, there were other unique approaches, one carried out by Frankovský et al.[3], where they investigate the vibration suppression capabilities of composite materials in comparison to other materials. This study calls for the investigation of shapes and the leaf springs' material properties, which is a unique approach to what most researchers are focusing on. Additionally, the review did not discuss much the vibration absorption properties of the springs an effect directly affected by specific strain energy of the material. This calls for further work to be carried out on the shape and other composite material compositions. The generalizability found in this review makes most of the work subject to limitations, for instance, studying one composite material and making conclusions based on the assumption that all composite materials are the same. This study aims to contribute to this growing area of research by exploring these gaps.

1. The performance of other composite materials, since there is a variety.

2. The study of different shapes of leaf springs and looking into their performances (optimization).

3. Study the vibration absorption capabilities of the leaf spring specifically focusing on strain energy for both dynamic loads and statistical loads. 


\section{References}

1. H. A. Al-Qureshi. (2001). Automobile leaf springs from composite materials. 118, 58-6.

2. J. J. Fuentes, H. J. Aguilar, J. A. Rodríguez, \& E. J. Herrera. (2009). Premature fracture in automobile leaf springs. 16 648-655.

3. P. Frankovský, W. Papacz, E. Tertel, \& P. Kuryło. (2014). Analysis of the Fatigue Life of Composite Leaf Springs. 611, 346-351. https://doi.org/10.4028/www.scientific.net/AMM.611.346.

4. M. Terrier. (1986). L'invention des ressorts de voiture. 39, 17-30. https://doi.org/10.3406/rhs.1986.4016.

5. Bending stress in leaf spring (2021).

6. M. A. Omar, A. A. Shabana, A. Mikkola, W.-Y. Loh, \& R. Basch. (2004). Multibody system modeling of leaf springs. 10, 1601-1638.

7. K. Badshar. (2021). Leaf spring - construction, working, advantages \& types. https://www.mechanicalpost.site/2021/02/leaf-spring.html (accessed 2021).

8. M. R. V. Rambade, M. N. S. Dudhale, M. S. K. Valawalkar, M. P. R. Yadav, \& M. M. M. Patil. Design. Analysis and Fabrication of Mono Leaf Spring using S-Glass Composite. (n.d.).

9. S. Tripathi \& R. K. Ambikesh. (2018). A study of composite materials for leaf spring. (n.d.).

10. P. Solanki \& A. K. Kaviti. Design and computational analysis of semi-elliptical and parabolic leaf spring. 5, 19441-19455.

11. A. Atig, R. Ben Sghaier, R. Seddik, \& R. Fathallah. (2018). A simple analytical bending stress model of parabolic leaf spring. 232, 1838-1850.

12. S. Bhattacharjee, S. Kanitkar, N. Kalasapur, \& V. Patel. Composite leaf spring. 2014 (2013).

13. S. Mouleeswaran. (2012). Design, manufacturing and testing of polymer composite multi-leaf spring for light passenger automobiles - a review (IntechOpen, 2012).

14. https://www.hkdivedi.com/2017/10/bending-stress-in-leaf-spring.html (accessed August 9, 2021).

15. T. W. Clyne \& D. Hull, An introduction to composite materials (Cambridge university press, 2019).

16. D. L. Mahanthi \& C. V. S. Murali. (2017). Design and analysis of composite Leaf Spring for light Weight Vehicle. 4, 147-152. https://doi.org/10.22161/ijaers.4.3.23.

17. P. Shakt. Vehicle leaf spring design, analysis \& comparison by using e-glass / epoxy and steel 65si7. 4 (2017) 105-110.

18. P. Dewanji. (2016). Design and analysis of composite leaf spring. 177-183.

19. V. Rai, Development of a Composite Leaf Spring for a Light Commercial Vehicle (Tata Magic). (2013).

20. F. Sedlacek, P. Bernardin, \& V. Lasova. Design of a composite leaf spring for railway vehicles. (2016) 493. https://doi.org/10.2507/27th.daaam.proceedings.074.

21. M.Venkatesan \& D. H. Devaraj. Design and analysis of composite leaf spring in light vehicle. 2 (2012) 213-218.

22. M. Venkatesan \& D. Helmen Devaraj, AH021213218. 2 (n.d.) 213.

23. P. Saini, A. Goel, \& D. Kumar. (2013) Design and analysis of composite leaf spring for light vehicles. 2 (2013) 1-10.

24. W. Papacz, E. Tertel, \& P. Kuryło. (2014). Performance comparison of conventional and composite leaf spring. (2014).

25. S. Varghese. (2019). Structural design and analysis of leaf spring made of composite material. 7, 3397-3409. https://doi.org/10.22214/ijraset.2019.5558

26. B. Göransson, No title. (2001). 